\title{
Crystallization and nucleation study of transition metal struvite and related compounds
}

\author{
Stephanos Karafiludis, Tomasz M. Stawski, Franziska Emmerling \\ BAM Berlin (Bundesanstalt für Materialforschung und -prüfung), Berlin, Germany; \\ stephanos.karafiludis@bam.de
}

The recycling of critical elements has crucial importance to maintain sustainable use of raw materials. Phosphorus $(\mathrm{P})$ is a sought-after limited natural resource due to its wide use in modern agriculture mainly as P-fertilizers. But it causes major problems for the environment such as eutrophication of ecosystems. In the future it could be depleted due to the high demand and declining natural phosphorite ore deposits. Therefore, the phosphorus recovery from mine and agricultural waste waters will be an important factor in preservation of the global consumption. The precipitation of M-struvite $\left(\mathrm{NH}_{4} \mathrm{MPO}_{4} \cdot 6 \mathrm{H}_{2} \mathrm{O}, \mathrm{M}^{2+}=\mathrm{Mg}^{2+}, \mathrm{Ni}^{2+}, \mathrm{Co}^{2+}\right)$ from waste waters is a promising P-recovery route. Besides avoidance of eutrophication due to extraction of excess phosphates and the restoration of the phosphorus resources the recovered M-struvites may be potentially be up-cycled for industrial applications e.g. Co and Ni-phosphate show excellent electrochemical properties for batteries or supercapacitors.

The precipitation process of $\mathrm{M}$-struvites is strongly dependent on the degree of supersaturation, $\mathrm{pH}$ and on the exchange ions $\mathrm{M}^{2+}$.The influence of these precipitation parameters on the crystal morphology and size of transition metal struvite has been investigated only to a limited extent. An optimization of the reaction conditions could lead to more efficient M-struvite precipitation and significantly improved P-recovery method.

We reveal the effect of different reaction conditions on the crystal shape and crystallite size of $\mathrm{M}$-struvites $\left(\mathrm{NH}_{4} \mathrm{MPO}_{4} \cdot 6 \mathrm{H}_{2} \mathrm{O}, \mathrm{M}=\right.$ $\left.\mathrm{Mg}^{2+}, \mathrm{Ni}^{2+}, \mathrm{Co}^{2+}\right)$. Furthermore, we characterize the coordination environment of the crystalline end products and their related phases [Co-dittmarite (COD) $\mathrm{NH}_{4} \mathrm{CoPO}_{4} \cdot \mathrm{H}_{2} \mathrm{O}$ and $\mathrm{Co}(\mathrm{II})$ phosphate octahydrate $\left.(\mathrm{CPO}) \mathrm{Co}_{3}\left(\mathrm{PO}_{4}\right)_{2} \cdot 8 \mathrm{H}_{2} \mathrm{O}\right]$. Due to the presence of various amorphous phases $\mathrm{pH}$ is changing significantly in the different systems. $\mathrm{Mg}$ - and Ni-struvite are stable in multiple concentrations of the educts and metal/phosphorus (M/P) ratios in contrast to Co-struvite which forms below $\mathrm{M} / \mathrm{P}$ ratios of 0.4 . A high $\mathrm{M} / \mathrm{P}$ ratio with high concentrations of the educts decrease the crystallite size and idiomorphism of the crystals while low M/P ratios with low concentrations of the educts increase the crystallite size and the euhedral formation of the crystal planes. In the (Ni, Co)-solid solutions $\mathrm{Ni}$ and $\mathrm{Co}$ are homogenously distributed in the crystals with similar Ni\# as in the aqueous solutions indicating no elemental fractionation in crystallization. $\mathrm{Ni}$ and $\mathrm{Co}$-struvite exhibit a more centrosymmetric coordination environment compared to their related phases of COD and CPO determined by EXAFS. The $\mathrm{CoO}_{6}$ octahedron expands slightly the ideal size of the struvite structure and decomposes to Co-dittmarite. From TEM analysis and $\mathrm{pH}$ measurements it is suggested that the crystallization of Ni- and Co-struvite follows a non-classical crystallization theory which consists of multiple nanophases, crystalline or amorphous, on the way to the final crystalline product.

Keywords: crystal engineering, Phosphorus recovery, transition metal struvite, non-classical crystallization theory 